\title{
The Effect of Tourism Clusters on U.S. Hotel Performance
}

Cornell Hospitality Quarterly $1-13$

(C) The Author(s) 2014 Reprints and permissions: sagepub.com/journalsPermissions.nav DOI: 10.1 I77//9389655/4557354 cqx.sagepub.com

(S)AGE

\author{
Angel Peiró-Signes ${ }^{1,2}$, Maria-del-Val Segarra-Oña ${ }^{1,2}$, \\ Luis Miret-Pastor ${ }^{3}$, and Rohit Verma ${ }^{4}$
}

\begin{abstract}
A cluster is a geographical concentration of interrelated firms. Cluster theory states that the synergies created inside the cluster (by the interactions between firms that compete and those that collaborate) enhance the productivity and innovation of firms and therefore their economic performance. While manufacturing industries have been widely studied from the clustering perspective, service clusters and specifically touristic clusters have received less attention. In this paper, we identify U.S. touristic clusters using a concentration measure, the Location Quotient. Then we check whether hotels located in touristic clusters obtain higher economic results than those hotels located in areas where the level of touristicrelated business concentration does not get the critical mass to consider it a cluster (instead of reducing their benefits due to the high level of competitors nearby). Our results find significant differences between the two sets of hotels. The effect is stronger for subsegments of hotels based on their star category, location, and management structure. Specifically, we demonstrate that the differences are more pronounced within luxury and upscale hotel categories and within chainmanaged hotels. The differences are less important in resort and airport locations than in small-metro/town, urban, and suburban areas. These results have important location implications for managers. They also contribute to understanding that economies of agglomeration lead to benefits from being located closely and in highly concentrated industries. But there is still a lot of research needed to better understand the relations between cooperation and competition within touristic clusters and how these enhance the economic performance of hotels.
\end{abstract}

\section{Keywords}

travel; tourism and hospitality clusters; hotels' economic performance; U.S. hotel industry

\begin{abstract}
Summary
A five-year analysis of tourism clusters finds that hotels generally benefit from being part of a cluster of tourist-related businesses. However, not all clusters or hotels benefit to the same extent-or at all in some cases. The cluster effect is stronger for luxury and upscale hotels, and chain-managed hotels also seem to benefit more than their independent competitors. Clusters in resort and airport locations seem to confer lower benefits than those in small-metro areas and towns, urban, or suburban areas. These results support the concept that economies of agglomeration lead to benefits from being co-located with other tourism businesses.
\end{abstract}

\section{Introduction}

The favorable economic effects of industrial clusters have been observed for nearly a century (Marshall 1920). Defined as a geographical concentration of interrelated firms and institutions (Porter, 1998), clusters result in enhanced returns and growth for firms in the cluster (for example, see Devereux, Griffith, and Simpson 2007; Ellison and Glaeser 1999).
The impact of clusters on firms' competitiveness and location planning have been extensively studied (e.g., Asheim, Cooke, and Martin 2008; Bannister and Stolp, 1994; Karaev, Kohand, and Szamosi 2007; Michaelides and Papazian 2007; Piperopoulos and Scase 2009; Puig, Marques, and Ghauri 2009; Saxenian 1996; Spencer et al. 2010). Although it is well established that location is a key element of a hotel's strategy (Crotts, Mason, and Davis 2009; Jones 1999), we have so far seen little research that analyzes the effects of agglomeration for the service industries in general, and travel, tourism, and hospitality businesses in particular.

\footnotetext{
Management Department, Universitat Politècnica de València, Spain ${ }^{2} \mathrm{CHR}$ Research Associates, Cornell University, USA

${ }^{3}$ Research Institute for Integrated Management of Coastal Areas-IGIC, Universitat Politècnica de València, Spain

${ }^{4}$ Cornell University, Ithaca, NY, USA
}

\section{Corresponding Author:}

Rohit Verma, School of Hotel Administration, Cornell University

Cornell University, 338 Statler Hall, Ithaca, NY 14853, USA.

Email: rv54@cornell.edu 
Similar to Porter (1998), we use quantitative indicators to identify geographical concentrations of hotels and related institutions or organizations ${ }^{1}$.Porter found that these socalled industrial clusters demonstrably enhance productivity, innovation, and competitiveness through (1) better access to well-trained human resources, (2) proximity to clients and faster detection of their needs, (3) proximity to suppliers, and (4) collaboration between clustered firms in improving operational, production, and logistical methods. The competition between producers provokes good ideas and leads to innovation. To see if this type of enhancement applies to tourism clusters, we analyze the effects on hotels by comparing their revenues over a five-year period.

It is of both academic and applied interest to understand the drivers of economic performance of hotels located within and outside of clusters (Kim and Oh 2004). In this paper, we seek to test empirically whether the benefits for hotels of being located in a geographically concentrated cluster leads to better economic performance.

To make this assessment, we test whether the performance of hotels located within geographical clusters differs from those outside a cluster by analyzing hotel performance data from 2007 through 2011. We use workforce data available from the U.S. Bureau of Labor Statistics to identify geographically concentrated tourism clusters (as in Delgado, Porter, and Stern 2013; Peters 2005, for example). We also use industry-wide multi-year revenue per available room (RevPAR) data available from STR Global to compare hotel performances within and outside clusters (http://www. strglobal.com).

\section{Studies on Clusters and Co-location}

Although hospitality firms have long formed de facto clusters in successful destinations that offer natural features or an attractive heritage, in recent years, there has been a growing interest in studying location economies, or the advantages of concentrating in a particular venue. Henderson (1986) demonstrated that concentrated industries are able to increase their factors of productivity, a finding that fits Marshall's (1920) concept of externality. If an externality is due to the ability to acquire more and better resources (Tallman et al. 2004), then it is a resource-based externality or supply externality (Flyer and Shaver 2003).

Several authors have shown that the geographic concentration of the tourism industry was largely justified by the presence of significant economies of location (Capone and Boix 2008) or the reduction of consumers' searching costs (Chung and Kalnins 2001). In addition to confirming the importance of the so-called externalities of demand (Canina, Enz, and Harrison 2005; Freedman and Kosova 2012; Kuah 2002), these factors also help to explain the territorial agglomerations of the hospitality industry (Scott and Laws 2008). Those studies set the stage for a deep analysis of the economic performance of the hospitality industry taking into consideration its particularities and location.

The effects of industrial agglomerations and clustering have been extensively studied in manufacturing and other related industries (e.g., Buenstorf and Klepper 2010; Enright 1999; Maine, Shapiro, and Vining 2010; Mukkala 2007; Ottaviano and Thisse 2001; Porter 2000). Generally speaking, these studies show that firms located within industrial clusters perform better than firms located outside clusters, primarily due to location-related synergistic effects, despite the proximity to competitors and the collaborative relations established (Erkus-Öztürk 2009; Novelli, Schmitz, and Spencer 2006; Yang 2012). Although it is tempting to extend these results to the service industries, we note that the travel, tourism, and hospitality industries' idiosyncratic factors may either enhance or reduce the cluster effects commonly observed in manufacturing-related industries.

Canina, Enz, and Harrison (2005) and Enz, Canina, and Liu (2008) made a significant contribution in this area by analyzing the effect of hotels' co-location on price within a geographical cluster. They found that the benefits of colocation were greater for hotels belonging to lower-segmented competitors than for more luxurious properties. To define their clusters, these authors assumed the already classified tracts defined by $\mathrm{STR}^{2}$. To take this analysis to the next step, our study uses empirical indicators to measure the geographical concentration. Another characteristic of Canina, Enz, and Harrison's paper is that the analysis only considers hotels. To extend this, we determine the geographical cluster of tourism businesses using well-known concentration measures (as the Bureau of Labor Statistics ${ }^{3}$ and The Harvard Institute for Strategy \& Competitiveness ${ }^{4}$ do, among others). Another interesting difference of our study is that we compare the economic performance of hotels belonging with those not belonging to clusters, considering their characteristics (i.e., market scale, company types, and location segments).

In light of the above, we argue that the synergistic effects that proximity generates justify the existence of localization economies. This should be reflected in the economic performance of the hotels located within tourism clusters. We believe that the synergistic effects are due to (1) the cooperation among dependent businesses (e.g., hotels and theatres, travel agencies, and public or private tourism developers), and (2) the vibrant competition among hotels that enhances productivity and innovation (Nordin 2003). Thus, our primary hypothesis tests the differences between the hotels located within and outside clusters and we formally state the following:

Hypothesis 1 (H1): The economic performance of hotels located within a geographical touristic cluster will be better than that of hotels located outside touristic clusters. 
While $\mathrm{H} 1$ tests the basic premise of the geographical cluster effect, we also want to examine whether hotels' particular characteristics can affect how the hotels benefit from being in a cluster.

The specific location of a cluster may influence how it affects hotels. For example, an airport hotel may not benefit from being close to a theater or a cinema, as the client may be just looking for a place to rest. However, having touristattracting businesses nearby may be interesting for a city hotel whose clients are looking for cultural, gastronomic or leisure activities.

In this context, we argue that hotels located in relatively isolated environments will benefit less from the cluster effect as they do not have economic generators or touristrelated businesses nearby. Moreover, hotels that do not benefit from other firms' cooperation (such as airport or interstate hotels) will have less economic benefits. Therefore, we propose the following hypothesis:

Hypothesis 2 (H2): Economic benefits derived from being in a cluster will be lower for hotels less dependent on other touristic activities.

At the same time, and following the line of research of Enz, Canina, and Liu (2008) and Canina, Enz, and Harrison (2005), the economic benefits of a cluster may depend on a hotel's chain scale (which Canina and Enz term strategy). Their studies show that the benefits of co-location are higher for economy hotels than for luxury and upscale ones. Contrary to that finding, we would expect that hotels with a differentiating strategy (upscale and luxury) would have greater ability to enhance their economic performance due to the benefits of co-location.

Hotels with a more developed service offering, with a better trained workforce, and with a clientele more interested in culture would have a higher absorptive capacity to integrate the possibilities that the cluster effect creates into their value creation strategy (Cohen and Levinthal 1990; Zahra and George 2002). Thus, we propose the following hypothesis:

Hypothesis 3 (H3): Economic benefits derived from being in a cluster will be higher for luxury and upscale hotels.

With regard to the hotel industry's complex ownership and management structures, scholars have argued that the nature of the management structure can explain performance differences between hotels (e.g., Botti, Briec, and Cliquet 2009; O'Neill and Carlbäck 2011; Perrigot, Cliquet, and Piot-Lepetit 2009). However, if indeed the geographical clustering effect is present, then we should be able to recognize it regardless of the ownership structure. Therefore, we propose the following hypothesis:
Hypothesis 4 (H4): Regardless of the ownership structure, the economic performance of hotels within a geographical cluster will be better than those outside the clusters.

\section{Research Approach}

The outline of our study is as follows. To explore our four hypotheses, we first develop a procedure for classifying locations as inside or outside a geographical cluster. After we develop a measure for cluster concentration, we identify various characteristics of hotels (i.e., location, quality or price segment, and ownership structure). Finally, we compare the economic performance of U.S. hotels for 2007 through 2011.

\section{Identification of Geographical Clusters}

A well-established approach for calculating the level of clustering within a specific region (for this study, a county) is to measure the relative specialization of an industry in a particular location with respect to the entire population of interest (in this case, the United States; see Lazzeretti and Capone 2006; O'Donoghue and Gleave 2004; Porter 2003; Segarra-Oña et al. 2012). The relative specialization of a territory (also called "relative concentration") is calculated through the Location Quotient (LQ) or Hoover-Balassa index. LQ measures the ratio between the local and national percentage of workforce attributable to an industry, as follows:

$$
L Q=\frac{\frac{E_{i s}}{E_{s}}}{\frac{E_{i}}{E}},
$$

So, the rate used to measure the specialization levels was the LQ, where Eis is the number of employees in state $S$ in sector $i$; $E S$ is the number of employees in state $S ; E i$ is the number of employees in the United States in sector $i$; and $E$ is the total number of employees in the United States.

LQ is one of the most used and well-supported measures of agglomeration (Delgado, Porter, and Stern 2013; MiretPastor, Segarra-Oña, and Peiró-Signes 2011; Segarra-Oña et al. 2012; U.S. Bureau of Labor Statistics ${ }^{3}$ ). Although the adequacy of the agglomeration indices is currently under discussion, according to Kominers (2008), no index is perfect to completely characterize the determinants of agglomeration across industries. We used the data available from the U.S. Bureau of Labor Statistics ${ }^{31}$ (last version available 2010) to calculate the LQ for each county within the United States.

Identifying tourism businesses involves certain assumptions, because there is no formal consensus to define tourism in a statistical fashion. To use appropriate statistical 
data for calculation, some authors, such as Lazzeretti and Capone (2006), identify tourism with hospitality. Other studies include industries such as transport and recreational activities (European Commission 2003). We adopted an intermediate position as in Leidner (2004), and applied the following Nomenclature statistique des Activités économiques dans la Communauté Européenne (NACE) codes: "Travel agencies and tour operators, 633; Hotel and other accommodations, 551-552; Restaurants, bars, canteens, catering, 553-555" and their 2003 North American Industry Classification System (NAICS) equivalent codes, "Arts, entertainment, and recreation (NAICS 71) and Accommodation and food services (NAICS 72)."

We use counties as the unit of analysis for calculating geographic cluster specialization, because that is the smallest U.S. geographical unit for which there are data of this type. As concentration standards have not been established formally for the hospitality industry, we set concentration cutoff levels for differentiating cluster areas based on other studies. Miller et al. (2001) suggested inferring the presence of a cluster when the LQ is above 1.25, while Malmberg and Maskell (2002) suggested using an LQ over 3. O'Donoghue and Gleave (2004) tried to resolve this problem by developing a standard location quotient (SLQ), which identifies those locations that show extraordinary LQ concentration values (i.e., their residuals show statistical significance at a $5 \%$ confidence level with a residual value over 1.96). A study on the Spanish touristic clusters (Segarra-Oña et al. 2012) helped us to decide the cutoff levels as follows. We classified counties with an LQ higher than 3 as "highly concentrated clusters," counties with SLQ values between 1.98 and 3 were classified as "medium concentrated clusters," and the counties with an LQ between 1.25 and 1.98 were classified as "low concentrated clusters." The regions with LQ scores below 1.25 were considered to be outside of clusters. Exhibit 1 includes a map of the United States color-coded to show the relative locations of high, medium, and low clusters and non-cluster counties. Note that high concentrated clusters may not occupy an entire county, even if that county is all in red (especially due to the size of counties in the Western United States). Likewise, a low-concentrated or no-cluster county may have small clusters that are not sufficient to register in this measurement.

Not surprisingly, the map shows strong clusters in some well-known tourist areas such as Las Vegas, Atlantic City, Orlando, Yellowstone (West Yellowstone, Idaho), Grand Canyon National Park (South Rim and Tusayan, Arizona), and the Hawaiian Islands.

\section{Hotel Performance Data and Analysis}

STR Global's hotel performance data includes annual and monthly supply, demand, and revenues for each property for our study period of 2007 through 2011. For our performance measure, we used the well-accepted RevPAR (see, for example, Chung and Kalnins 2001). Furthermore, RevPAR is closely related to gross operating profit per available room (GOPPAR; Canina, Enz, and Harrison 2005), which takes into account operation costs.

We restructured the database so that data for each property were considered as a single case and created performance variables on a time basis (e.g., RevPAR2007 represents room RevPAR for the year 2007). The database contained comparable information for 27,208 hotel properties within the United States.

Next, we identified hotel properties within one of the four cluster categories based on the ZIP codes for the counties in question. To match ZIP codes with counties, we used U.S. Postal Service ZIP Codes compiled by the U.S. Census Bureau for 1999, the last year it tabulated its decennial data by ZIP code. The match of counties and ZIP codes put 4,339 properties into a county with one of the three cluster densities, while the remaining 22,867 properties were located outside of counties having clusters.

\section{Results and Discussion}

We conducted a series of analyses of variance (ANOVAs) to test the cluster effect on hotel performance by comparing RevPAR values for the properties inside the three cluster categories with those outside of any cluster. Then we split the sample according to location, ownership structure, and price and market segment categories. For the hotels' location, we used the commonly accepted categories for hotels developed by STR (namely, urban, suburban, airport, resort, small metro or town, and interstate). We distinguished three categories of ownership structure: chain-managed, franchised, or independent properties. We also used STR's hotel segment categories to clarify differences according to the property segment. Finally, we designated properties within clusters as belonging to a "high," "medium," or "low" concentrated cluster, and we used Scheffe's pairwise comparison procedure following the ANOVA. Summarized ANOVA results with sample sizes, means, and $F$ values are reported in Exhibit 2.

Generally speaking, hotels within clusters show significantly $(p<.001)$ greater RevPAR performance than those outside clusters over the five-year period. Mean RevPAR for properties in clusters was between $\$ 6.10$ (USD) and $\$ 7.70$ higher than RevPAR for properties outside the clusters, supporting H1, this paper's primary hypothesis.

Segmented results for specific locations show significant differences $(p<.001)$ for airport, resort, and small-metro or town locations, but not always in the expected direction. We found that clustered airport and resort hotels do not perform as well as one would expect based on clustering theory. Airport properties in clusters, for example, perform on 


\section{Exhibit 1:}

\section{Geographical Clusters within the United States for the Hospitality, Travel, and Tourism Industry.}

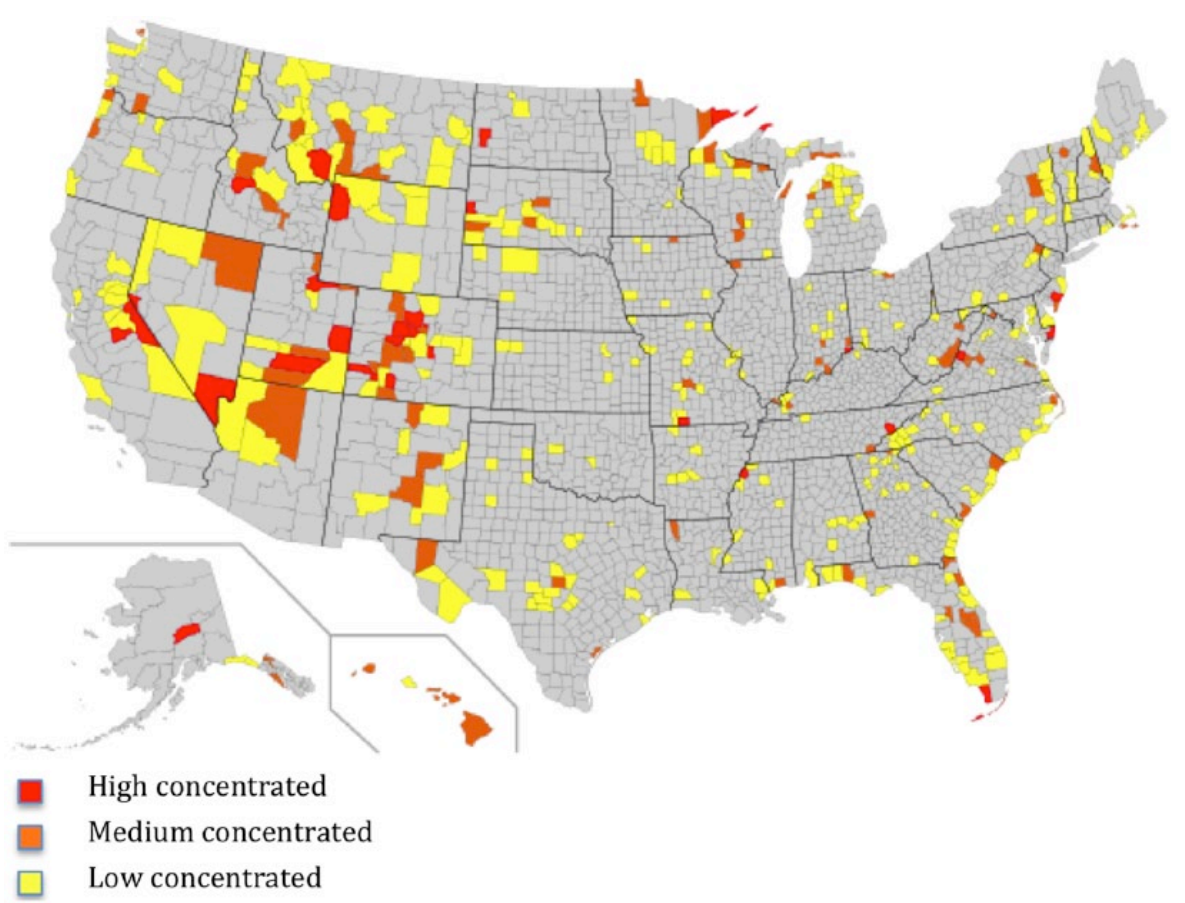

average between $\$ 6.70$ and $\$ 9.30$ below airport hotels outside the clusters. Similarly, in-cluster resort hotels' mean RevPARs are significantly and consistently lower than those of resort properties outside the clusters. However, small-metro or town hotels in clusters performed on average $\$ 7.90$ to $\$ 10.90$ better than properties located in small towns outside tourism clusters. Overall, these results provide support for the second hypothesis, regarding the effects of clustering on hotels that do not rely on other tourism resources. Neither airport hotels nor resorts depend on secondary tourism activities to the extent that other types of property do. Resorts make a point of being as comprehensive as possible, and we have already mentioned the key function of airport hotels, which is to house travelers in transit.

These differences between hotels in clusters and those outside are depicted in Exhibit 3. We used solid lines to represent the mean RevPAR values for in-cluster hotels and dotted lines for out-of-cluster hotels. For comparison purposes, we established the same scale ratio in all the graphs, so we can visually compare the differences between the two groups among different segments.

The results using average daily rate as a measure of product quality or segmentation demonstrated consistently higher performances in luxury and upscale properties within clusters (compared with similar hotels outside of clusters).
Luxury properties in clusters achieved between $\$ 11.30$ and $\$ 18.10$ over the RevPAR values of luxury properties outside the clusters, and the difference for upscale hotels ranged from $\$ 5.70$ to $\$ 9.10(p<.001)$. These findings validate $\mathrm{H}$, particularly because midscale and economy in-cluster properties were not able to improve RevPAR over similar-level properties outside clusters. As shown in Exhibit 4, there is virtually no difference in the mean RevPAR values of the two groups.

With regard to the ownership structure of the hotels, only chain-managed hotels in clusters had consistently higher RevPARs, ranging $\$ 20.70$ to $\$ 27.00$ than those outside these clusters $(p<.001)$, while franchisee-managed and independent hotels in clusters were not able to improve significantly over those outside the clusters. We note, however, that RevPAR values for independents in tourism clusters were higher than those outside (Exhibit 5). That said, these differences were significant only in 2011. Because these results suggest the presence of a moderating effect of ownership structure above and beyond the clustering effect, $\mathrm{H} 4$ is not validated. We are nevertheless able to draw important conclusions from these results.

Finally, we see that hotels do better in clusters with higher concentrations. To determine this, we segmented hotels in clusters according to the cluster concentration based on the LQ value of the county. Scheffe's pairwise 


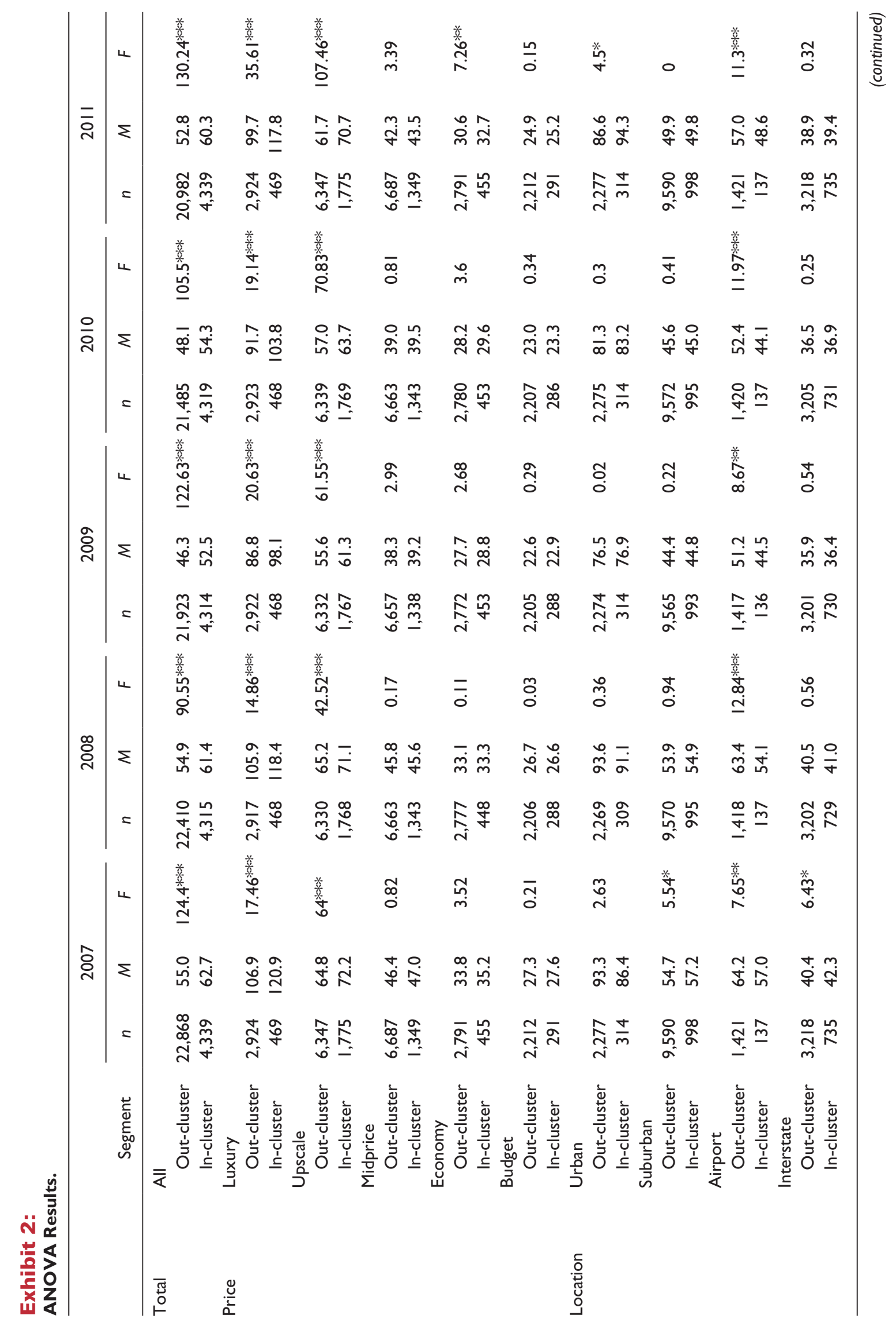




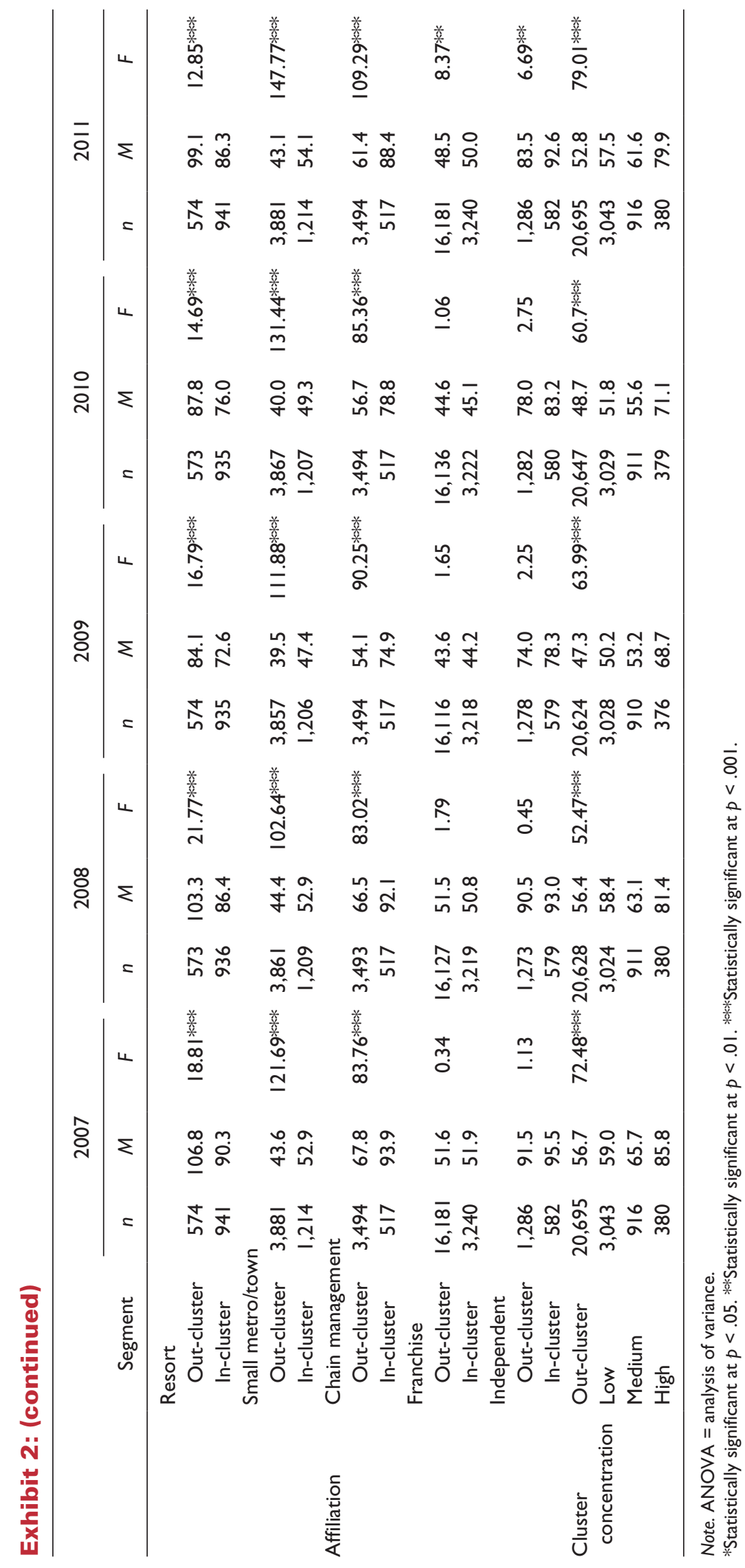




\section{Exhibit 3:}

Average RevPAR In-Cluster versus Out-Cluster by Location.

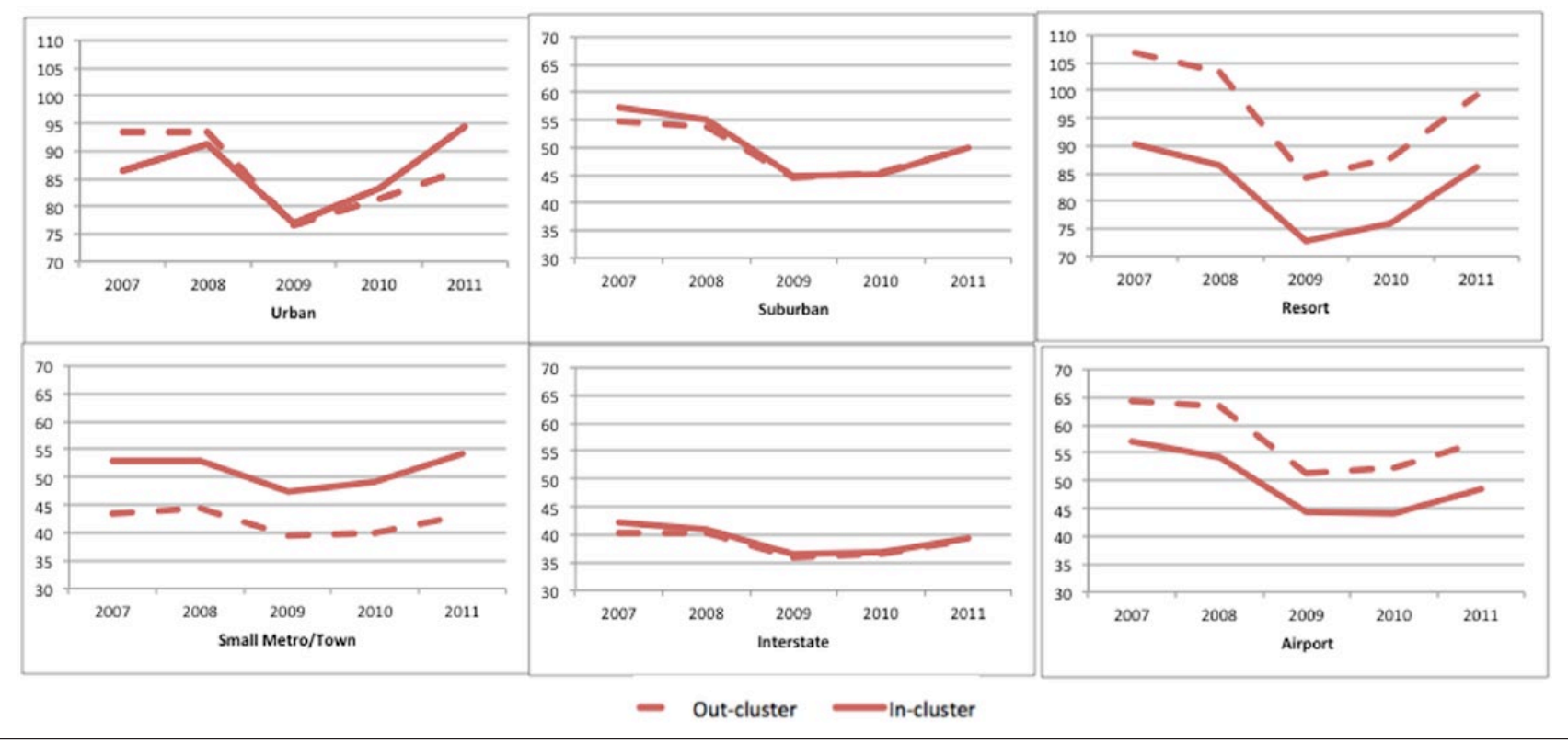

Note. RevPAR = revenue per available room

\section{Exhibit 4:}

Average RevPAR In-Cluster versus Out-Cluster by Price Segment.

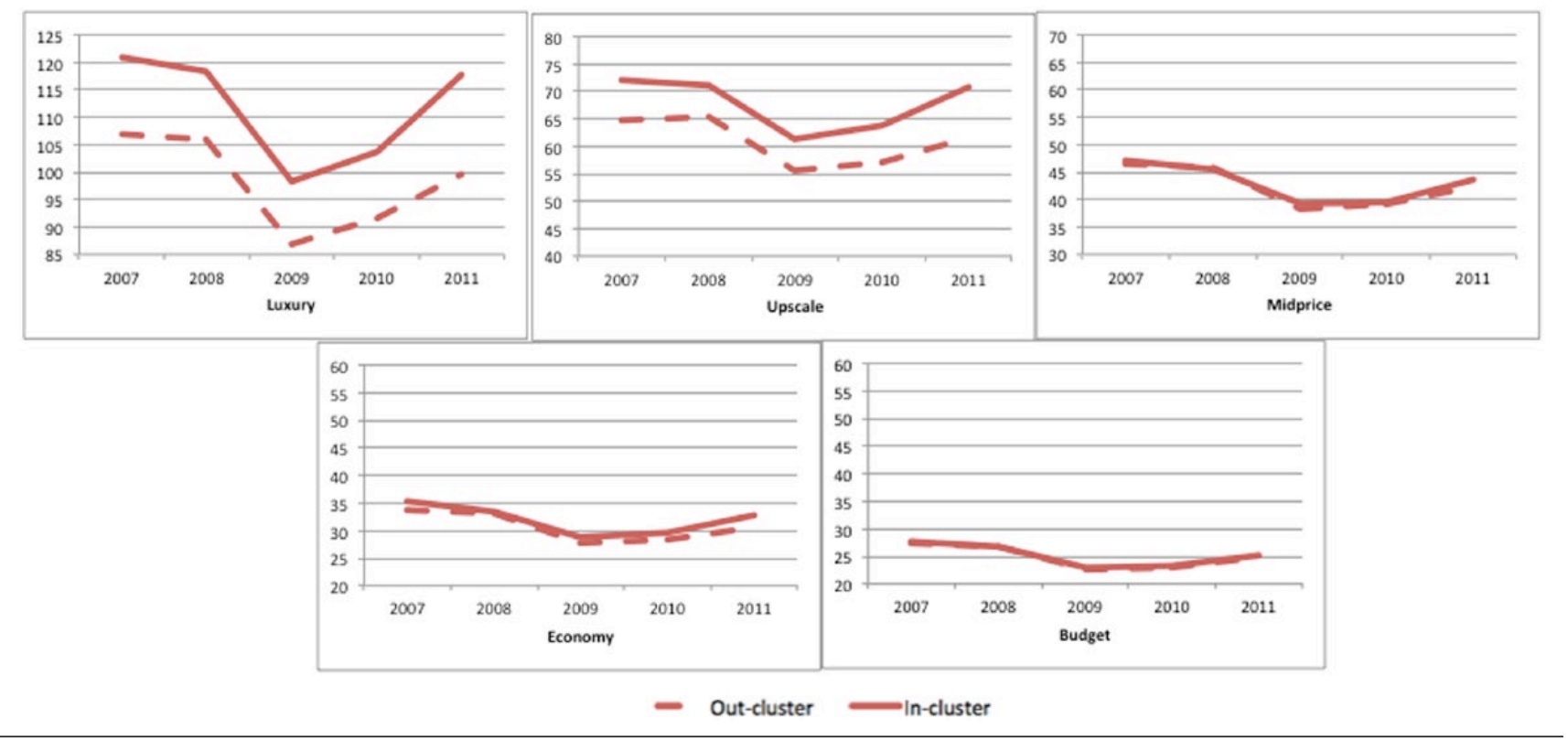

Note. RevPAR = revenue per available room .

comparison shows significant differences $(p<.001)$ between out-of-cluster properties and in-cluster properties. Exhibit 6 shows this result: the higher the concentration, the higher the RevPAR leve.
Even though ANOVA results indicate that, in general terms, RevPAR values are higher in properties located in tourism clusters, we cannot determine whether those results are caused by being located in clusters. Therefore, to address 


\section{Exhibit 5:}

Average RevPAR In-Cluster versus Out-Cluster by Ownership Affiliation.

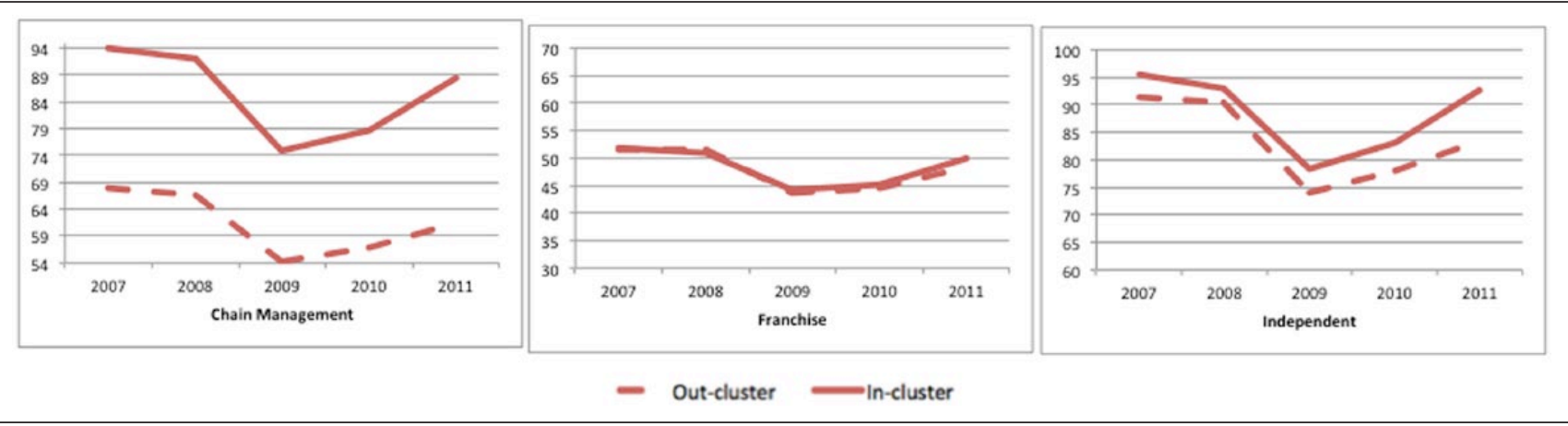

Note. RevPAR = revenue per available room

\section{Exhibit 6:}

Average RevPAR In-Cluster Concentration versus OutCluster.

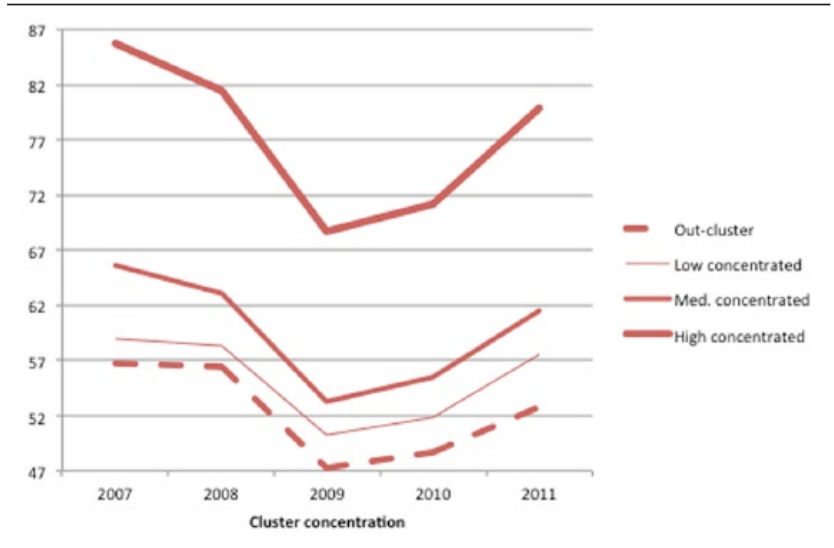

Note. RevPAR = revenue per available room .

this issue, we conducted a regression analysis study creating dummy variables to isolate the effect of location (urban, suburban, airport, interstate, and small metro or town), affiliation (chain, franchised, and independent), and price level (luxury, upscale, midprice, economy, and budget). For the sake of clarity, we only report models for 2011, but we received similar results for the previous years. In the regression models, RevPAR is considered as being dependent on the cluster membership, the property location, affiliation, and price level.

The proposed model is as follows, being $\mathrm{C}$ the constant and $\mathrm{E}$ the error:

$$
\begin{aligned}
\text { RevPAR }= & C+\beta_{1} \text { Chain }+\beta_{2} \text { Franchise }+\beta_{3} \text { Luxury }+ \\
& \beta_{4} \text { Upscale }+\beta_{5} \text { Midprice }+\beta_{6} \text { Economy }+ \\
& \beta_{7} \text { Urban }+\beta_{8} \text { Suburban }+\beta_{9} \text { Airport }+ \\
& \beta_{10} \text { Interstate }+\beta_{11} \text { Resort }+\beta_{12} \text { Cluster }+E .
\end{aligned}
$$

The value of $\beta_{12}$ helps to determine whether the clustering itself creates a difference in the hotels' performance indicators. Similarly, $\beta_{2}$ and $\beta_{3}$ will help to evaluate whether property affiliation has a significant influence on RevPAR. For this analysis, we consider independent budget properties located in small towns outside the cluster as the base category.

We assessed the significance of dummy variables as a set, using the $R^{2}$-change method and ignoring the individual $t$-tests produced by default for each dummy $\beta$ coefficient. We then can evaluate the relative predictive power of location, affiliation, price level, and cluster membership by analyzing beta weights in the regression.

Regression results in Exhibit 7 indicate that acting in an isolated way, cluster membership has a positive effect on RevPAR, confirming our first hypothesis. Chain-managed and franchised hotels act negatively on RevPAR (compared with independents) in accordance with ANOVA results. This indicates that the advantage that properties get from increasing occupancies at whatever rate the brand sets is not enough to overcome the higher prices achieved by independents, even if they have lower occupancy. Regression results on location confirmed also that urban and resort locations generally perform better than the other locations, while interstate locations have the lowest RevPAR. Finally, it is no surprise that price level has a positive effect on RevPAR.

Although the regression analysis confirms the ANOVA results, we need to incorporate the joint effect of cluster membership and location, affiliation, and price level to assess the other hypotheses. Therefore, we added a set of interaction terms to the model. The significance of the change of $R^{2}$ for the two equations (i.e., the equation with the interaction terms and the equation without them) indicates that the new models constitute a significantly better fit. This indicates a linear relationship of each of these variables to the independent variables.

Analyzing cross effects, we find that price level empowers cluster effect on RevPAR. The higher the price level, the 
Exhibit 7:

Linear Regressions and Linear Regressions Considering Interaction Terms.

\begin{tabular}{|c|c|c|c|c|c|c|}
\hline & RevPAR & ADR & Occ & RevPAR & ADR & Occ \\
\hline Constant & 36.182 & 76.51 & 0.465 & 34.779 & 73.407 & 0.459 \\
\hline Chain & $-6.417(-0.056)$ & $-26.256(-0.18)$ & $0.132(0.281)$ & $-6.837(-0.06)$ & $-25.742(-0.177)$ & $0.137(0.293)$ \\
\hline Franchise & $-19.873(-0.206)$ & $-36.68 \mathrm{I}(-0.297)$ & $0.031(0.078)$ & $-18.304(-0.189)$ & $-33.188(-0.268)$ & $0.035(0.088)$ \\
\hline Luxury & $65.378(0.561)$ & $84.32(0.566)$ & $0.123(0.257)$ & $63.436(0.545)$ & $81.136(0.544)$ & $0.126(0.263)$ \\
\hline Upscale & $39.64 \mid(0.467)$ & $52.177(0.48)$ & $0.098(0.28)$ & $38.503(0.453)$ & $49.667(0.457)$ & $0.102(0.292)$ \\
\hline Midprice & $20.359(0.235)$ & $29.329(0.264)$ & $0.028(0.078)$ & $20.179(0.233)$ & $28.875(0.26)$ & $0.03(0.083)$ \\
\hline Economy & $9.133(0.074)$ & $14.62(0.093)$ & $-0.008(-0.016)$ & $8.703(0.07 I)$ & I $3.848(0.088)$ & $-0.007(-0.014)$ \\
\hline Urban & $25.055(0.187)$ & $22.248(0.13)$ & $0.082(0.149)$ & $26.383(0.197)$ & $25.521(0.149)$ & $0.077(0.139)$ \\
\hline Suburban & I.95I (0.024) & $-2.018(-0.019)$ & $0.042(0.126)$ & $3.099(0.038)$ & $-0.08(-0.00 \mathrm{I})$ & $0.042(0.125)$ \\
\hline Airport & $4.553(0.027)$ & $-4.156(-0.019)$ & $0.089(0.127)$ & $6.142(0.036)$ & $-1.616(-0.007)$ & $0.088(0.126)$ \\
\hline Interstate & $-2.175(-0.02)$ & $-5.531(-0.039)$ & $0.004(0.01)$ & $-1.269(-0.012)$ & $-3.753(-0.027)$ & $0.003(0.008)$ \\
\hline Resort & $24.87(0.146)$ & $31.716(0.146)$ & $0.053(0.076)$ & $28.255(0.166)$ & $36.866(0.17)$ & $0.06(0.085)$ \\
\hline Cluster & $1.752(0.015)$ & $4.738(0.033)$ & $-0.012(-0.025)$ & $5.248(0.046)$ & 11.961 (0.082) & 0.021 (0.045) \\
\hline Cluster $\times$ Chain & & & & $7.973(0.026)$ & $7.134(0.018)$ & $-0.026(-0.021)$ \\
\hline $\begin{array}{l}\text { Cluster } \times \\
\text { Franchise }\end{array}$ & & & & $-6.58 I(-0.05 I)$ & $-14.735(-0.09)$ & $-0.013(-0.025)$ \\
\hline Cluster $\times$ Luxury & & & & I4.563 (0.045) & $24.66(0.06)$ & $-0.026(-0.02)$ \\
\hline Cluster $\times$ Upscale & & & & $7.485(0.044)$ & I7.343 (0.08) & $-0.032(-0.046)$ \\
\hline Cluster $\times$ Midprice & & & & $2.033(0.011)$ & $5.649(0.023)$ & $-0.017(-0.022)$ \\
\hline $\begin{array}{l}\text { Cluster } \times \\
\text { Economy }\end{array}$ & & & & $3.495(0.011)$ & $6.945(0.017)$ & $-0.012(-0.009)$ \\
\hline Cluster $\times$ Urban & & & & $-6.983(-0.018)$ & $-20.689(-0.04 I)$ & 0.05 I (0.032) \\
\hline $\begin{array}{l}\text { Cluster } \times \\
\text { Suburban }\end{array}$ & & & & $-6.106(-0.028)$ & $-9.524(-0.034)$ & $-0.003(-0.003)$ \\
\hline Cluster $\times$ Airport & & & & $-10.394(-0.018)$ & $-15.058(-0.02)$ & $0.001(0.001)$ \\
\hline $\begin{array}{l}\text { Cluster } \times \\
\text { Interstate }\end{array}$ & & & & $-3.964(-0.015)$ & $-7.593(-0.023)$ & $0.004(0.003)$ \\
\hline Cluster $\times$ Resort & & & & $-11.523(-0.05)$ & $-18.543(-0.063)$ & $-0.01(-0.01)$ \\
\hline ANOVA F & $1,605.582 * * *$ & $1,600.794 * * *$ & $552.185^{* * * *}$ & 850.668 & 857.968 & 290.667 \\
\hline$R^{2}$ & $.396 * * *$ & $.395^{* * *}$ & $.184^{* * * *}$ & .399 & $.40 \mathrm{I}$ & .185 \\
\hline$F$ change & & & & $16.789 * * *$ & $29.202 * * *$ & $4.570 * * *$ \\
\hline$R^{2}$ change & & & & $.004 * * *$ & $.007 * * *$ & $.001 * * *$ \\
\hline
\end{tabular}

Note. ANOVA = analysis of variance; RevPAR = revenue per available room; ADR = Average Daily Rate; Occ= Occupancy. Values in parentheses refer to standardized beta coefficients.

*Statistically significant at $p<.05$. **Statistically significant at $p<.0$ I. *** Statistically significant at $p<.00$ I.

bigger the impact of cluster membership on RevPAR, validating $\mathrm{H} 3$.

Regarding affiliation, being chain managed in a cluster decreases the RevPAR gap over independent properties, which indicates a bigger cluster effect in chain-managed hotels. The cluster effect in franchised hotels is slightly smaller than in independents and its value is negative. This indicates a strong positive cluster effect for chain-managed properties, a small positive effect for independents, and a small negative effect for franchised properties. Therefore, we can say that affiliation moderates the cluster effect on performance, but the cluster effect is not positive whatever the affiliation, rejecting $\mathrm{H} 4$.

Finally, cluster membership has a heterogeneous impact on RevPAR. According to the results, the cluster effect is clearly stronger in interstate and small-metro or town properties and lower in resorts and airport properties. Thus, economic benefits derived from being in a cluster are lower for hotels that are less dependent on other tourism activities, confirming $\mathrm{H} 2$.

\section{Conclusion}

The analysis of hotels located inside and outside of clusters suggested that being located in a cluster improves a hotel's economic performance, in line with previous studies' results applied to service industries (Lazzeretti, Boix, and Capone 2008) and in support of our first hypothesis. Segmented results showed that luxury and upscale properties in clusters performed consistently better than similar properties 
outside clusters. This confirmed our third hypothesis, but it also highlights the need for more research to see the extent to which well-structured hotels, with human and financial resources and previous experience, are taking advantage of their ability to identify and apply knowledge, as suggested by absorptive capacity theory (Cohen and Levinthal 1990; Zahra and George 2002). Likewise, chain-managed hotels inside clusters excel compared with chain-managed properties outside clusters. More to the point, the chain properties prospered when they were inside a cluster, while independent and franchised hotels did not. This finding echoes that of O'Neill and Carlbäck (2011), who pointed out that the intangible asset value of hotel brands (e.g., shared resources, guest loyalty programs, and yield management systems) allows chain-managed hotels to achieve better economic performance (both in recession and growth economic cycles). Further research is needed here to disentangle the practical implications.

Hotels in clusters in small-metro areas and towns performed consistently higher than their comparable segment properties out of the clusters, as compared with resort or airport locations. Those town-based hotels are more dependent on other tourism facilities, such as restaurants, shopping areas, nature spots, and recreation, to attract guests. Further research should analyze the type of relationship involved here.

These results have interesting implications for owners and operators, because the importance of location is amplified by the cluster effect. This suggests that hotel owners and operators should collaborate with other firms in the region to enhance the cluster concentration as a higher degree of clustering is also correlated with higher performance. Although the hotel industry is famously competitive, the cluster effect argues for an element of cooperation over competition. In this regard, the traditional microeconomic model of competition is not applicable due to the need to cooperate to promote a destination (Jackson and Murphy 2006). Research suggests that the collaborative and competitive interactions between local firms create geographic externalities that play an important role when tourism destinations compete with each other globally (Erkus-Öztürk 2009; Ferreira and Estevao 2009; Lazzeretti, Capone, and Cintiet 2010; Novelli et al., 2006; Richards and Wilson 2006).

When firms allocate resources, they consider a wide variety of variables such as, for example, economic, legal, and political issues, accessibility, basic services, site costs, environmental regulations, labor availability, taxes, and incentives (Jiang, Frazier, and Prater 2006; MacCarthy and Atthirawong 2003). However, a certain level of competitive advantage resides in the "know-how," in the capacities, in the information, in the motivation, or in the geographic externalities produced (Lazzeretti, Capone and Cinty, 2010). All of these are aspects related to the local business environment (Ingram and Roberts 2000) that the competitors located outside the cluster find it more difficult to obtain (Nassimbeni 2003). These results open a deep line of study. Intangible relations established among the different businesses that constitute a tourism cluster should be identified. This will let both policymakers implicated in the promotion of the destinations and business managers take decisions that enhance the economic performance of hotels, restaurants, and other tourism-related activities.

The challenge now is to use both qualitative and quantitative methodologies to analyze the relational function of the cluster - that is, how and why agglomeration economies arise. The roles of public, tourist, and educational institutions need to be disentangled.

One other aspect of this study is that it opens a window on the impact of the financial crisis on hotel performance between 2007 and 2008. All segments show a similar pattern, with a RevPAR decline until 2009 and a recovery period that goes through 2011. However, the smaller differences between the in-cluster and out-of-cluster properties that occurred in 2009 (shown in Exhibit 2) suggest that incluster hotels are more sensitive to a crisis environment than out-of-cluster properties. The clustered hotels also recovered more quickly, as shown by the increasing gap between the two groups in 2010, which continues in 2011. Moreover, significant differences appear in 2011 in segments such as economy, urban, franchise, and independent. These results suggest that properties in clusters recover more rapidly than properties outside clusters, and that opens a new line of study and further research is needed.

\section{Declaration of Conflicting Interests}

The author(s) declared no potential conflicts of interest with respect to the research, authorship, or publication of this article.

\section{Funding}

The author(s) received no financial support for the research, authorship, or publication of this article. The authors would like to thank the Center for Hospitality Research at Cornell University that hosted A. Peiró and M. Segarra as Visiting Scholars The authors also want to thank Donald Schnedeker from the Nestle library at the School of Hotel Administration at Cornell University and Russ Lloyd, and STR for providing us with the data used in this paper.

\section{Notes}

1. See Harvard University/Porter's website, http://www.isc. hbs.edu/competitiveness-economic-development/researchand-applications/Pages/cluster-studies.aspx (see submarket) submarket: a geographic area that is a subset of a market. A market is made up of one or more submarkets.

2. http://www.strglobal.com/resources/glossary/en-gb (see sub market)

3. http://www.bls.gov/data/\#calculators

4. http://www.clustermapping.us (see submarket) submarket-a geographic area that is a subset of a market. A market is made up of one or more submarkets 


\section{References}

Asheim, B., P. Cooke, and R. Martin. 2008. Clusters and regional development: Critical reflections and explorations. Economic Geography 84 (1): 109-12.

Bannister, G. J., and C. Stolp. 1994. Regional concentration and efficiency in Mexican manufacturing. European Journal of Operational Research 80 (3): 672-90.

Botti, L., W. Briec, and G. Cliquet. 2009. Plural forms versus franchise and company-owned systems: A DEA approach of hotel chain performance. Omega 37 (3): 566-78.

Buenstorf, G., and S. Klepper. 2010. Why does entry cluster geographically? Evidence from the US tire industry. Journal of Urban Economics 68 (2): 103-14.

Canina, L., K. Enz, and J. Harrison. 2005. Agglomeration effects and strategic orientations: Evidence from the U.S. lodging industry. Academy of Management Journal 48 (4): 565-81.

Capone, F., and R. Boix. 2008. Sources of growth and competitiveness of local tourist production systems: An application to Italy (1991-2001). The Annals of Regional Science 42 (1): 209-24.

Chung, W., and A. Kalnins. 2001. Agglomeration effects and performance: A test of the Texas lodging industry. Strategic Management Journal 22 (10): 969-88.

Cohen, W. M., and D. A. Levinthal. 1990. Absorptive capacity: A new perspective on learning and innovation. Administrative Science Quarterly 35 (1): 128-52.

Crotts, J. C., P. R. Mason, and B. Davis. 2009. Measuring guest satisfaction and competitive position in the hospitality and tourism industry: An application of stance-shift analysis to travel blog narratives. Journal of Travel Research 48 (2): 139-51.

Delgado, M., M. E. Porter, and S. Stern. 2013. Defining clusters of related industries. Mimeo. Boston: Institute for Strategy and Competitiveness, Harvard Business School.

Devereux, M. P., R. Griffith, and H. Simpson. 2007. Firm location decisions, regional grants and agglomeration externalities. Journal of Public Economics 91 (3): 413-35.

Ellison, G., and E. L. Glaeser. 1999. The geographic concentration of industry: Does natural advantage explain agglomeration? The American Economic Review 89 (2): 311-16.

Enright, M. J. 1999. Regional clusters and firm strategy. In The dynamic firm, ed. A. Chandler, O. Solvell, and P. Hagstrom, 315-42. Oxford: Oxford University Press.

Enz, C., L. Canina, and Z. Liu. 2008. Competitive dynamics and pricing behavior in U.S. hotels: The role of co-location. Scandinavian Journal of Hospitality and Tourism 8 (3): 230-50.

Erkus-Öztürk, H. 2009. The role of cluster types and firm size in designing the level of network relations: The experience of the Antalya tourism region. Tourism Management 30 (4): 589-97.

European Commission. 2003. Structure, performance and competitiveness of European tourism and its enterprises. Luxembourg: European Communities.

Ferreira, J. M., and C. M. S. Estevao. 2009. Regional competitiveness of a toruism cluster: a conceptual model proposal (In portuguese, Competitividade regional de um cluster de turismo: uma proposta de modelo conceptual). Encontros Científicos 5:37-51.
Flyer, F., and J. M. Shaver. 2003. Location choices under agglomeration externalities and strategic interaction. In Geography and strategy-Advances in strategic management, vol. 20, ed. A. C. Baum and O. Sorenson, 193-214. Oxford: JAI Press.

Freedman, M., and R. Kosova. 2012. Agglomeration, product heterogeneity, and firm entry. Journal of Economic Geography 12 (3): 601-26.

Henderson, J. V. 1986. Urbanization in a developing country: City size and population composition. Journal of Development Economics 22 (2): 269-93.

Ingram, P., and P. W. Roberts. 2000. Friendships among competitors in the Sydney hotel industry. American Journal of Sociology 106 (2): 387-423.

Jackson, J., and P. Murphy. 2006. Clusters in regional tourism destinations: An Australian case. Annals of Tourism Research 33 (4): 1018-35.

Jiang, B., G. V. Frazier, and E. L. Prater. 2006. Outsourcing effects on firms' operational performance: An empirical study. International Journal of Operations \& Production Management 26 (12): 1280-300.

Jones, P. 1999. Operational issues and trends in the hospitality industry. International Journal of Hospitality Management 18 (4): 427-42.

Karaev, A., S. C. L. Kohand, and L. T. Szamosi. 2007. The cluster approach and SME competitiveness: A review. Journal of Manufacturing Technology Management 18 (7): 818-35.

Kim, B. Y., and H. Oh. 2004. How do hotel firms obtain a competitive advantage? International Journal of Contemporary Hospitality Management 16 (1): 65-71.

Kominers, S. D. 2008. Measuring agglomeration. Harvard Urban and Social Economics Seminar (Economics 2800b) http:// www.scottkom.com/articles/measure_agglomeration.pdf.

Kuah, A. T. H. 2002. Cluster theory and practice: Advantages for the small business locating in a vibrant cluster. Journal of Research in Marketing and Entrepreneurship 4 (3): 206-28.

Lazzeretti, L., R. Boix, and F. Capone. 2008. Do creative industries cluster? Mapping creative local production systems in Italy and Spain. Industry and Innovation 15 (5): 549-67.

Lazzeretti, L., and F. Capone. 2006. Identification and analysis of tourist local systems: An application to Italy (1996-2001). In Tourism local systems and networking, ed. L. Lazzeretti and C. Petrillo, 25-42. Amsterdam: Elsevier.

Lazzeretti, L., F. Capone, and T. Cinti. 2010. The regional development platform and "related variety": Some evidence from art and food in Tuscany. European Planning Studies 18 (1): $27-45$.

Leidner, R. 2004. The European tourism industry: A multi-sector with dynamic markets. Luxembourg: European Commission.

MacCarthy, B. L., and W. Atthirawong. 2003. Factors affecting location decisions in international operations-A Delphi study. International Journal of Operations \& Production Management 23 (7): 794-818.

Maine, E. M., D. M. Shapiro, and A. R. Vining. 2010. The role of clustering in the growth of new technology-based firms. Small Business Economics 34 (2): 127-46.

Malmberg, A., and P. Maskell. 2002. The elusive concept of location economies: Towards a knowledge-based theory of spatial clustering. Environment and Planning A 34 (3): 429-49.

Marshall, A. 1920. Principles of economics: An introductory volume. 8th ed. London: Macmillan, 
Michaelides, Z. M., and A. Papazian. 2007. Benefits of clustering for SME's suppliers in the aerospace and defence sector through the adaptation of enterprise portals. International Journal of Services and Operations Management 3 (2): 152-71.

Miller, P., R. Botham, H. Gibson, R. Martin, and B. Moore. 2001. Business clusters in the UK-A first assessment (Main report). London: Department of Trade and Industry.

Miret-Pastor, L., M. Segarra-Oña, and A. Peiró-Signes. 2011. Identification of service sectors and high technology in Valencia: A new cluster mapping [Identificación de sectores de servicios y de alta tecnología en la Comunidad Valenciana: Un nuevo cluster mapping]. Revista de Estudios Regionales 90:71-96. (In Spanish).

Mukkala, K. 2007. Agglomeration economies in the Finnish manufacturing sector. Applied Economics 36 (21): 2419-27.

Nassimbeni, G. 2003. Local manufacturing systems and global economy: Are they compatible?: The case of the Italian eyewear district. Journal of Operations Management 21 (2): 151-71.

Nordin, S. 2003. Tourism clustering and innovation-Paths to economic growth and development. Ostersund, Sweden: European Tourism Research Institute, Mid-Sweden University.

Novelli, M., B. Schmitz, and T. Spencer. 2006. Networks, clusters and innovation in tourism: A UK experience. Tourism Management 27 (6): 1141-52.

O'Donoghue, D., and B. Gleave. 2004. A note on methods for measuring industrial agglomeration. Regional Studies 38 (4): 419-27.

O’Neill, J. W., and M. Carlbäck. 2011. Do brands matter? A comparison of branded and independent hotels' performance during a full economic cycle. International Journal of Hospitality Management 30 (3): 515-21.

Ottaviano, G. I. P., and J. Thisse. 2001. On economic geography in economic theory: Increasing returns and pecuniary externalities. Journal of Economic Geography 1 (2): 153-79.

Perrigot, R., G. Cliquet, and I. Piot-Lepetit. 2009. Plural form chain and efficiency: Insights from the French hotel chains and the DEA methodology. European Management Journal 27 (4): 268-80.

Peters, D. J. 2005. Using labor-based industry complexes for workforce development in Missouri. Economic Development Quarterly 19 (2): 138-56.

Piperopoulos, P., and R. Scase. 2009. Competitiveness of small and medium sized enterprises: Towards a two dimensional model of innovation and business clusters. International Journal of Business Innovation and Research 3 (5): 479-99.

Porter, M. E. 1998. Clusters and the new economics on competition. Harvard Business Review 76 (6): 77-90.

Porter, M. E. 2000. Location, competition, and economic development: Local clusters in a global economy. Economic Development Quarterly 14 (1): 15-34.
Porter, M. E. 2003. The economic performance of regions. Regional Studies 37 (6-7): 549-78.

Puig, F., H. Marques, and P. N. Ghauri. 2009. Globalization and its impact on operational decisions: The role of industrial districts in the textile industry. International Journal of Operations \& Production Management 29 (7): 692-719.

Richards, G., and J. Wilson. 2006. Developing creativity in tourist experiences: A solution to the serial reproduction of culture? Tourism Management 27 (6): 1209-20.

Saxenian, A. 1996. Regional advantage: Culture and competition in Silicon Valley and Route 128. Cambridge: Harvard University Press.

Scott, N., and E. Laws. 2008. Knowledge sharing in tourism and hospitality. Journal of Quality Assurance in Hospitality \& Tourism 7 (1-2): 1-12.

Segarra-Oña, M., L. Miret-Pastor, A. Peiro-Signes, and R. Verma. 2012. The effects of localization on economic performance: Analysis of Spanish tourism clusters. European Planning Studies 20 (8): 1319-34.

Spencer, G. M., T. Vinodrai, M. S. Gertler, and D. A. Wolfe. 2010. Do clusters make a difference? Defining and assessing their economic performance. Regional Studies 44 (6): 697-715.

Tallman, S., M. Jenkins, N. Henry, and S. Pinch. 2004. Knowledge, clusters and competitive advantage. Academy of Management Review 29 (2): 258-71.

Yang, Y. 2012. Agglomeration density and tourism development in China: An empirical research based on dynamic panel data model. Tourism Management 33 (6): 1347-59.

Zahra, S. A., and G. George. 2002. Absorptive capacity: A review, reconceptualization, and extension. Academy of Management Review 27 (2): 185-203.

\section{Author Biographies}

Ángel Peiró-Signes, Ph.D., is an assistant professor at the Universitat Politècnica de València (anpeisig@omp.upv.es) and Research Associate of the CHR, Cornell University, USA (ap479@cornell.edu).

María-del-Val Segarra-Oña, Ph.D., is an associate professor at the Universitat Politècnica de València (maseo@omp.upv.es). She is also a research associate of the CHR, Cornell University, USA.

Luis Miret-Pastor, Ph.D., is an assistant professor at Universitat Politècnica de València (luimipas@esp.upv.es).

Rohit Verma is a professor of service operations management at the School of Hotel Administration (SHA) (rv54@cornell.edu). He served as the executive director of the CHR, Cornell University, during 2009-2012 and is currently the Singapore Tourism Board Distinguished Professor in Asian Hospitality Management. 